\title{
Association of Drug Metabolic Enzyme Genetic Polymorphisms and Adverse Drug Reactions in Patients Receiving Rifapentine and Isoniazid Therapy for Latent Tuberculosis
}

\author{
Ya-Yen Yu ${ }^{1,2}$, Shih-Ming Tsao ${ }^{3,4}$, Wen-Ta Yang ${ }^{5}$, Wei-Chang Huang ${ }^{6,7,8,9}{ }^{\oplus}$, Ching-Hsiung Lin ${ }^{10}$,

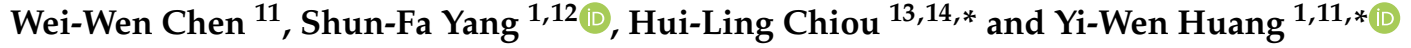 \\ 1 Institute of Medicine, Chung Shan Medical University, Taichung 402, Taiwan; yy68642@gmail.com (Y.-Y.Y.); \\ ysf@csmu.edu.tw (S.-F.Y.) \\ 2 Department of Clinical Laboratory, Changhua Hospital, Changhua 513, Taiwan \\ 3 Division of Chest, Department of Internal Medicine, Chung Shan Medical University Hospital, Taichung 402, \\ Taiwan; tsmhwy@ms24.hinet.net \\ 4 Institute of Biochemistry, Microbiology and Immunology, Chung Shan Medical University, \\ Taichung 402, Taiwan \\ 5 Department of Internal Medicine, Taichung Hospital, Ministry of Health and Welfare, Taichung 403, Taiwan; \\ taic3057@gmail.com \\ 6 Division of Chest Medicine, Department of Internal Medicine, Taichung Veterans General Hospital, \\ Taichung 407, Taiwan; huangweichangtw@gmail.com \\ 7 Department of Medical Technology, Jen-Teh Junior College of Medicine, Nursing and Management, \\ Miaoli 356, Taiwan \\ 8 Department of Life Sciences, National Chung Hsing University, Taichung 402, Taiwan \\ 9 Department of Industrial Engineering and Enterprise Information, Tunghai University, Taichung 407, Taiwan \\ 10 Division of Chest, Changhua Christian Hospital, Changhua 500, Taiwan; 47822@cch.org.tw \\ 11 Department of Health, Pulmonary and Critical Care Unit, Changhua Hospital, Changhua 500, Taiwan; \\ sweefa818@gmail.com \\ 12 Department of Medical Research, Chung Shan Medical University Hospital, Taichung 402, Taiwan \\ 13 School of Medical Laboratory and Biotechnology, Chung Shan Medical University, Taichung 402, Taiwan \\ 14 Department of Clinical Laboratory, Chung Shan Medical University Hospital, Taichung 402, Taiwan \\ * Correspondence: hlchiou@csmu.edu.tw (H.-L.C.); hiwen1533@gmail.com (Y.-W.H.)
}

Received: 11 November 2019; Accepted: 25 December 2019; Published: 27 December 2019

\begin{abstract}
Weekly rifapentine and isoniazid therapy (3HP) is the most frequent treatment for latent tuberculosis infection (LTBI). However, the association between major adverse drug reactions (ADRs) and drug metabolic enzyme single-nucleotide polymorphisms (SNPs) remains unclear. In this study, 377 participants who received the $3 \mathrm{HP}$ regimen were recruited and examined for genotyping of CYP5A6, CYP2B6, CYP2C19, CYP2E1, and NAT2 SNPs. In our study, 184 participants (48.4\%) developed ADRs. Moreover, CYP2C19 rs4986893 (TT vs. CC+CT, odds ratio [OR] [95\% CI]: 2.231 [1.015-4.906]), CYP2E1 rs2070676 (CC vs. CG+GG, OR [95\% CI]: 1.563 [1.022-2.389]), and CYP2E1 rs2515641 (CC vs. CT+TT, OR [95\% CI]: 1.903 [1.250-2.898]) were associated with ADR development. In conclusion, CYP2C19 and CYP2E1 SNPs may provide useful information regarding ADRs in LTBI patients receiving the $3 \mathrm{HP}$ regimen.
\end{abstract}

Keywords: drug metabolic enzymes; polymorphism; latent tuberculosis; adverse drug reaction 


\section{Introduction}

Tuberculosis (TB) is still prevalent worldwide. Up to one-third of the world's population is estimated to be infected with Mycobacterium tuberculosis [1]. Additionally, although infected individuals have no signs or symptoms of TB disease and are not infectious, they still have a risk of active TB infection and becoming infectious. In Taiwan, TB ranks the highest for the number of new cases and is the main cause of death annually from communicable diseases in Taiwan.

A comprehensive effort to control TB by implementing directly observed therapy (DOT), a short-course program, for all patients with TB has been implemented since 2006 in Taiwan to reduce the incidence to half, from 67.4 per 100,000 population to 33.7 per 100,000 population, by 2016 . Although the incidence rate has declined, it gradually slowed down to 43.9 per 100,000 population by 2016, less than half of the target. Thus, intensified efforts to reduce TB morbidity and transmission by implementing more laboratory diagnoses, active-TB case identification, and latent TB infection (LTBI) treatment have been commenced since 2016.

Apart from the traditional LTBI treatment regimen, that is, isoniazid (INH) $300 \mathrm{mg}$ daily for 9 months (9H), in 2011 the Centers for Disease Control and Prevention recommended a short-course combination regimen of once-weekly INH and rifapentine for 12 weeks (3HP) through DOT [2,3]. Compared with other regimens, the $3 \mathrm{HP}$ regimen has practical advantages, such as a shorter treatment period, higher completion rate, and cost effectiveness [4]. Typically, the hepatotoxicity risk during LTBI treatment is much lower in the $3 \mathrm{HP}$ regimen than in the $9 \mathrm{H}$ regimen [5]. Therefore, the $3 \mathrm{HP}$ regimen was initiated in Taiwan in 2013, as it is in one of the high prevalence areas for viral hepatitis. However, the incidence of flu-like syndrome, one of the side effects of the 3HP regimen, is much higher in Taiwan $(8 \%$ vs. $2.2 \%)[6,7]$ than in other countries. The occurrence of flu-like syndrome is also the common reason for the noncompliance of patients with the $3 \mathrm{HP}$ regimen.

Flu-like syndrome is one of the adverse reactions of rifapentine. Rifapentine induces cytochrome P450 enzymes and can also accelerate the metabolism of certain drugs, such as birth control pills and antiretroviral drugs [8]. By contrast, INH is the inhibitor of cytochrome P450 enzymes [9,10]. Therefore, clinicians should pay more attention to drug-drug interactions. Another study reported that women, Caucasians, elderly individuals, and individuals with a low body mass index (BMI) have a higher risk of developing systemic drug reactions after the administration of the 3HP regimen; however, the mechanism underlying this increased risk remains unclear [6]. Therefore, in this study, eight polymorphisms of drug metabolic enzyme genes, namely CYP5A6 rs28399433, CYP2B6 rs8192709, CYP2C19 rs4986893, CYP2C19 rs12248560, CYP2E1 rs2070676, CYP2E1 rs2515641, NAT2 rs1495741, and NAT2 rs1799930, were examined to study their associations with susceptibility to adverse drug reactions (ADRs) in the $3 \mathrm{HP}$ regimen in patients with latent TB infection in Taiwan.

\section{Materials and Methods}

\subsection{Study Design}

This was a multicenter observational study including close contacts aged $>12$ years and selecting individuals not resistant to INH and rifampin between February 2017 and October 2018. Participants received $15 \mathrm{mg} / \mathrm{kg}$ of INH (maximum dose of $900 \mathrm{mg}$ ) and rifapentine (maximum dose of $900 \mathrm{mg}$ ). Basic information, namely age, sex, BMI, ethnicity, education, comorbidities, medications, occupation, and compliance with therapy, were recorded for each participant. Dose adherence was assessed by DOT, and ADR monitoring was based on patients' self-report. ADRs were recorded after receiving the first dose each week until two weeks after the treatment. The onset time, duration, and severity of ADRs, such as flu-like syndrome and skin symptoms, were recorded. Severity was defined by the common toxicity criteria of the Cancer Therapy Evaluation Program. The association between the cause of incomplete treatment and single-nucleotide polymorphisms (SNPs) was analyzed on the basis of the aforementioned data. Written informed consent was obtained from each participant enrolled 
in this study. This study was approved by the Institutional Review Board of Chung Shan Medical University Hospital (CSMUH No: CS16131).

\subsection{Sample Preparation and DNA Extraction}

Peripheral blood specimens were collected from patients with LTBI for genomic DNA extraction. Whole blood samples were placed in ethylenediaminetetraacetic (EDTA)-containing tubes and were centrifuged at $3000 \mathrm{rpm}$ for $10 \mathrm{~min}$. Genomic DNA extraction was performed using QIAamp DNA blood mini kits (Qiagen, Valencia, CA, USA) as previously described [11]. Extracted DNA was dissolved in Tris-EDTA (TE) buffer and was applied as DNA template in the following process of polymerase chain reactions.

\subsection{Drug Metabolic Enzyme SNP Genotyping}

Assessment of allelic discrimination for CYP5A6 rs28399433 (assay ID: C_30634332_10), CYP2B6 rs8192709 (assay ID: C_2818162_20), CYP2C19 rs4986893 (assay ID: C_27861809_10), CYP2C19 rs12248560 (assay ID: C_469857_10), CYP2E1 rs2070676 (assay ID: C_16026001_20), CYP2E1 rs2515641 (assay ID: C_16026002_10), NAT2 rs1495741 (assay IDs: C_8684110_10), and NAT2 rs1799930 (assay IDs: C_1204091_10) SNPs were performed using the TaqMan assay with an ABI StepOne Software v2.3 Real-Time PCR System. The real-time PCR consisted of initial denaturation at $95^{\circ} \mathrm{C}$ for $10 \mathrm{~min}$, followed by 40 cycles at $95^{\circ} \mathrm{C}$ for $15 \mathrm{~s}$ and finally $1 \mathrm{~min}$ at $60^{\circ} \mathrm{C}$. Generated data were collected and further evaluated using the SDS 7000 series software (Applied Biosystems, Foster City, CA, USA).

\subsection{Statistical Analysis}

Continuous variables were determined using Student's $t$-test, and categorical variables were determined using the chi-squared test or Fisher's exact test. The chi-squared test was also applied to determine the prevalence of all drug metabolic enzyme gene polymorphisms, such as CYP2E1 genotype, between the non-ADR and ADR group. Multiple unconditional logistic regression analyses were performed to estimate odds ratios and their $95 \%$ confidence intervals. Two-tailed $p$ values $<0.05$ were considered to be statistically significant.

\section{Results}

A total of $377 \mathrm{~TB}$ patients were recruited and administered the $3 \mathrm{HP}$ regimen. Of these 377 participants, $337(89.3 \%)$ completed the treatment, $29(7.7 \%)$ discontinued treatment owing to ADRs, $8(2.1 \%)$ switched to the $9 \mathrm{H}$ regimen due to ADRs, and $3(0.8 \%)$ transferred to another facility or refused further treatment (Table 1$)$. In the total sample, the mean age was 45.7 years, 208 participants $(55.2 \%)$ were women, 144 participants (38.2\%) had comorbidities, and 184 (48.8\%) developed ADRs (Table 2). ADRs occurred in 184 participants $(48.4 \%)$, and 596 adverse drug events were reported. Most of the ADRs were Grade 1 (77.68\%), followed by Grade 2 ADRs (20.63\%). Grade 3 ADRs were observed most frequently in patients with flu-like symptoms $(80 \%)$, one patient with urticaria, and one patient with hepatotoxicity.

Table 1. Characteristics and treatment outcomes of the enrolled participants.

\begin{tabular}{ccccc}
\hline$(\boldsymbol{n}=\mathbf{3 7 7 )}$ & $\begin{array}{c}\text { Treatment } \\
\text { Completed }\end{array}$ & $\begin{array}{c}\text { Interrupted Due } \\
\text { to Side Effects }\end{array}$ & $\begin{array}{c}\text { Switched to 9H Due } \\
\text { to Side Effects }\end{array}$ & Other * \\
\hline $\begin{array}{c}\text { Number } \\
\%\end{array}$ & 337 & 29 & 8 & 3 \\
& $89.4 \%$ & $7.7 \%$ & $2.1 \%$ & $0.8 \%$ \\
\hline
\end{tabular}

* Transferred to other medical facility, refused further treatment. 
Table 2. Clinical characteristics and laboratory data in 377 patients.

\begin{tabular}{cccc}
\hline Variable & $(\boldsymbol{n}=\mathbf{3 7 7 )}$ & $\begin{array}{c}\text { Non-ADR } \\
(\boldsymbol{n}=\mathbf{1 9 3})\end{array}$ & $\begin{array}{c}\text { ADR } \\
(\boldsymbol{n}=\mathbf{1 8 4})\end{array}$ \\
\hline Age (year) & & & \\
$\leqq 35$ & 96 & 53 & 43 \\
$36-55$ & 169 & 88 & 81 \\
$56-64$ & 83 & 37 & 46 \\
$\geqq 65$ & 29 & 15 & 14 \\
\hline Gender & & & \\
Male & 169 & 101 & 68 \\
Female & 208 & 92 & 116 \\
Body mass index (kg/m $\left.{ }^{2}\right)$ & 24.9 & 25 & 24.7 \\
AST (U/L) & 25.11 & 24.95 & 25.32 \\
ALT (U/L) & 27.08 & 26.98 & 27.1 \\
\hline
\end{tabular}

$\begin{array}{cccc}\text { Comorbidity }(n=144) & & & \\ \text { Hypertension } & 46 & 22 & 9 \\ \text { Diabetes mellitus } & 21 & 12 & 6 \\ \text { HBV infection } & 17 & 11 & 4 \\ \text { Heart disease } & 8 & 4 & 4 \\ \text { Thalassemias } & 5 & 1 & 2 \\ \text { Hyperlipidemia } & 4 & 2 & 0 \\ \text { Allergic rhinitis } & 4 & 4 & 3 \\ \text { Insomnia } & 3 & 0 & 1 \\ \text { Hyperthyroidism } & 3 & 2 & 4 \\ \text { Gastric ulcer } & 4 & 0 & 1 \\ \text { Hyperthyroidism } & 3 & 2 & 2 \\ \text { Hepatitis C } & 2 & 0 & 2 \\ \text { Gout } & 2 & 0 & 2 \\ \text { Lung cancer } & 2 & 0 & 1 \\ \text { Dementia } & 1 & 0 & 1 \\ \text { Breast cancer } & 2 & 1 & 1 \\ \text { Proctitis } & 1 & 0 & 1 \\ \text { Fatty liver } & 1 & 0 & 0 \\ \text { Hyperuricemia } & 1 & 1 & 6\end{array}$

ADR: adverse drug reaction; AST: aspartate transaminase; ALT: alanine transaminase. HBV: Hepatitis B virus; Others: epilepsy, urticaria, cerebral neurasthenia, cerebral palsy, fibromyalgia, anemia, aplastic anemia, gall stone, hemochromatosis. Data are number.

The genotypes of CYP5A6, CYP2B6, CYP2C19, CYP2E1, and NAT2 SNPs in the non-ADR and ADR groups are shown in Table 3. In the non-ADR and ADR groups, the highest distribution frequencies of the drug metabolic enzyme genetic polymorphisms rs28399433, rs8192709, rs4986893, rs12248560, rs2070676, rs2515641, rs1495741, and rs1799930 were homozygous for AA, TT, GG, CC, CC, CC, GA, and GG, respectively. As shown in Table 3, patients with CYP2B6 polymorphic rs8192709 TC or TC+CC, CYP2E1 polymorphic rs2070676 CG or CG+GG, CYP2E1 polymorphic rs2515641 CT or CT+TT genotypes exhibited significantly $(p<0.05)$ higher frequencies, 2.355 -fold (95\% CI: 1.037-5.351), 2.231-fold (95\% CI: 1.015-4.906), 1.594-fold (95\% CI: 1.031-2.464), 1.563-fold (95\% CI: $1.022-2.389$ ), 1.850-fold (95\% CI: 1.193-2.870), and 1.903-fold (95\% CI: 1.250-2.898) respectively, of developing ADRs compared with their corresponding wild type (WT) homozygotes. 
Table 3. Single nucleotide polymorphism frequencies of five drug-metabolic genes in 377 patients.

\begin{tabular}{|c|c|c|c|c|c|}
\hline Variable & $\begin{array}{c}\text { ALL } \\
(n=377)\end{array}$ & $\begin{array}{c}\text { Non-ADR } \\
(n=193)\end{array}$ & $\begin{array}{c}\text { ADR } \\
(n=184)\end{array}$ & OR (95\% C.I.) & $p$ Value \\
\hline \multicolumn{6}{|c|}{ CYP5A6 (rs28399433) } \\
\hline $\mathrm{A} / \mathrm{A}$ & $235(62.3 \%)$ & $116(60.1 \%)$ & $119(64.7 \%)$ & 1.000 (reference) & \\
\hline $\mathrm{C} / \mathrm{A}$ & $100(26.5 \%)$ & $54(28.0 \%)$ & $46(25.0 \%)$ & $0.830(0.519-1.327)$ & $p=0.437$ \\
\hline $\mathrm{C} / \mathrm{C}$ & $42(11.2 \%)$ & $23(11.9 \%)$ & 19 (10.3\%) & $0.805(0.417-1.557)$ & $p=0.520$ \\
\hline $\mathrm{C} / \mathrm{A}+\mathrm{C} / \mathrm{C}$ & $142(37.7 \%)$ & $77(39.9 \%)$ & $65(35.3 \%)$ & $0.823(0.542-1.249)$ & $p=0.360$ \\
\hline \multicolumn{6}{|c|}{ CYP2B6 (rs8192709) } \\
\hline $\mathrm{T} / \mathrm{T}$ & $347(92.0 \%)$ & $183(94.8 \%)$ & $164(89.1 \%)$ & 1.000 (reference) & \\
\hline $\mathrm{T} / \mathrm{C}$ & $28(7.5 \%)$ & $9(4.7 \%)$ & $19(10.3 \%)$ & $2.355(1.037-5.351)$ & $p=0.041$ * \\
\hline $\mathrm{C} / \mathrm{C}$ & $2(0.5 \%)$ & $1(0.5 \%)$ & $1(0.6 \%)$ & $1.116(0.069-17.983)$ & $p=0.938$ \\
\hline $\mathrm{T} / \mathrm{C}+\mathrm{C} / \mathrm{C}$ & $30(8.0 \%)$ & $10(5.2 \%)$ & $20(10.9 \%)$ & $2.231(1.015-4.906)$ & $p=0.046^{*}$ \\
\hline \multicolumn{6}{|c|}{ CYP2C19 (rs4986893) } \\
\hline $\mathrm{G} / \mathrm{G}$ & $342(90.7 \%)$ & $180(93.3 \%)$ & $162(88.0 \%)$ & 1.000 (reference) & \\
\hline G/A & $34(9.0 \%)$ & $12(6.2 \%)$ & $22(12.0 \%)$ & $2.037(0.977-4.247)$ & $p=0.058$ \\
\hline $\mathrm{A} / \mathrm{A}$ & $1(0.3 \%)$ & $1(0.5 \%)$ & $0(0.0 \%)$ & - & - \\
\hline $\mathrm{G} / \mathrm{A}+\mathrm{A} / \mathrm{A}$ & $35(9.3 \%)$ & $13(6.7 \%)$ & $22(12.0 \%)$ & $1.880(0.917-3.854)$ & $p=0.085$ \\
\hline \multicolumn{6}{|c|}{ CYP2C19 (rs12248560) } \\
\hline $\mathrm{C} / \mathrm{C}$ & $375(99.5 \%)$ & $191(99.0 \%)$ & $184(100.0 \%)$ & 1.000 (reference) & \\
\hline $\mathrm{T} / \mathrm{C}$ & $2(0.5 \%)$ & $2(1.0 \%)$ & $0(0.0 \%)$ & - & - \\
\hline $\mathrm{T} / \mathrm{T}$ & $0(0 \%)$ & $0(0.0 \%)$ & $0(0.0 \%)$ & - & - \\
\hline $\mathrm{T} / \mathrm{C}+\mathrm{T} / \mathrm{T}$ & $2(0.5 \%)$ & $2(1.0 \%)$ & $0(0.0 \%)$ & - & - \\
\hline \multicolumn{6}{|c|}{ CYP2E1 (rs2070676) } \\
\hline $\mathrm{C} / \mathrm{C}$ & $243(64.5 \%)$ & $134(69.4 \%)$ & 109 (59.3\%) & 1.000 (reference) & \\
\hline $\mathrm{C} / \mathrm{G}$ & $124(32.9 \%)$ & $54(28.0 \%)$ & $70(38.0 \%)$ & $1.594(1.031-2.464)$ & $p=0.036$ * \\
\hline G/G & $10(2.6 \%)$ & $5(2.6 \%)$ & $5(2.7 \%)$ & $1.229(0.347-4.356)$ & $p=0.749$ \\
\hline $\mathrm{c} / \mathrm{G}+\mathrm{G} / \mathrm{G}$ & $134(35.5 \%)$ & $59(30.6 \%)$ & $75(40.8 \%)$ & $1.563(1.022-2.389)$ & $p=0.039$ * \\
\hline \multicolumn{6}{|c|}{ CYP2E1 (rs2515641) } \\
\hline $\mathrm{C} / \mathrm{C}$ & $232(61.5 \%)$ & $133(68.9 \%)$ & $99(53.8 \%)$ & 1.000 (reference) & \\
\hline $\mathrm{C} / \mathrm{T}$ & $126(33.4 \%)$ & $53(27.5 \%)$ & $73(39.7 \%)$ & $1.850(1.193-2.870)$ & $p=0.006$ * \\
\hline $\mathrm{T} / \mathrm{T}$ & $19(5.1 \%)$ & $7(3.6 \%)$ & $12(6.5 \%)$ & $2.303(0.875-6.062)$ & $p=0.091$ \\
\hline $\mathrm{C} / \mathrm{T}+\mathrm{T} / \mathrm{T}$ & $145(38.5 \%)$ & $60(31.1 \%)$ & $85(46.2 \%)$ & $1.903(1.250-2.898)$ & $p=0.003$ * \\
\hline \multicolumn{6}{|c|}{ NAT2 (rs1495741) } \\
\hline $\mathrm{G} / \mathrm{G}$ & $116(30.8 \%)$ & $63(32.6 \%)$ & $53(28.8 \%)$ & 1.000 (reference) & \\
\hline G/A & $166(44.0 \%)$ & $94(48.7 \%)$ & $72(39.1 \%)$ & $0.910(0.565-1.467)$ & $p=0.700$ \\
\hline $\mathrm{A} / \mathrm{A}$ & $95(25.2 \%)$ & $36(18.7 \%)$ & $59(32.1 \%)$ & 1.948 (1.121-3.385) & $p=0.018^{*}$ \\
\hline $\mathrm{G} / \mathrm{A}+\mathrm{A} / \mathrm{A}$ & $261(69.2 \%)$ & $130(67.4 \%)$ & $131(71.2 \%)$ & $1.198(0.773-1.857)$ & $p=0.420$ \\
\hline \multicolumn{6}{|c|}{ NAT2 (rs1799930) } \\
\hline $\mathrm{G} / \mathrm{G}$ & $219(58.1 \%)$ & $112(58.0 \%)$ & 107 (58.1\%) & 1.000 (reference) & \\
\hline $\mathrm{G} / \mathrm{A}$ & $128(33.9 \%)$ & $62(32.1 \%)$ & $66(35.9 \%)$ & $1.114(0.720-1.724)$ & $p=0.627$ \\
\hline $\mathrm{A} / \mathrm{A}$ & $30(8.0 \%)$ & $19(9.9 \%)$ & $11(6.0 \%)$ & $0.606(0.275-1.333)$ & $p=0.213$ \\
\hline $\mathrm{G} / \mathrm{A}+\mathrm{A} / \mathrm{A}$ & $158(41.9 \%)$ & $81(42.0 \%)$ & $77(41.8 \%)$ & $0.995(0.661-1.498)$ & $p=0.981$ \\
\hline
\end{tabular}

Note: * and bold text indicate a significant association with $p$-value $<0.05$.

The allele frequencies of CYP5A6, CYP2B6, CYP2C19, CYP2E1, and NAT2 SNPs in patients in the non-ADR and ADR groups are shown in Table 4. Results indicated that patients with the CYP2E1 polymorphic rs2515641 T allele and NAT2 polymorphic rs1495741 A allele exhibited significantly $(p<0.05)$ higher frequencies, 1.704-fold (95\% CI: 1.200-2.421) and 1.415-fold (95\% CI: 1.062-1.885), respectively, of developing ADRs compared with their corresponding WT homozygotes (Table 4). 
Table 4. Single nucleotide polymorphism frequencies of five drug-metabolic genes in 377 patients.

\begin{tabular}{|c|c|c|c|c|c|}
\hline Variable & $\begin{array}{c}\text { ALL } \\
(n=754)\end{array}$ & $\begin{array}{c}\text { Non-ADR } \\
(n=386)\end{array}$ & $\begin{array}{c}\text { ADR } \\
(n=368)\end{array}$ & OR (95\% C.I.) & $p$ Value \\
\hline \multicolumn{6}{|c|}{ CYP5A6 (rs28399433) } \\
\hline A allele & $570(75.6 \%)$ & $286(74.1 \%)$ & $284(77.2 \%)$ & 1.000 (reference) & \\
\hline C allele & $184(24.4 \%)$ & $100(25.9 \%)$ & $84(22.8 \%)$ & $0.846(0.606-1.181)$ & $p=0.325$ \\
\hline \multicolumn{6}{|c|}{ CYP2B6 (rs8192709) } \\
\hline $\mathrm{T}$ allele & $722(95.8 \%)$ & $375(97.2 \%)$ & 347 (94.3\%) & 1.000 (reference) & \\
\hline C allele & $32(4.2 \%)$ & $11(2.8 \%)$ & $21(5.7 \%)$ & $2.063(0.980-4.341)$ & $p=0.056$ \\
\hline \multicolumn{6}{|c|}{ CYP2C19 (rs4986893) } \\
\hline G allele & $718(95.2 \%)$ & $372(96.4 \%)$ & $346(94.0 \%)$ & 1.000 (reference) & \\
\hline A allele & $36(4.8 \%)$ & $14(3.6 \%)$ & $22(6.0 \%)$ & $1.690(0.851-3.355)$ & $p=0.134$ \\
\hline \multicolumn{6}{|c|}{ CYP2C19 (rs12248560) } \\
\hline C allele & $752(99.7 \%)$ & $384(99.5 \%)$ & $368(100.0 \%)$ & 1.000 (reference) & \\
\hline $\mathrm{T}$ allele & $2(0.3 \%)$ & $2(0.5 \%)$ & $0(0.0 \%)$ & - & - \\
\hline \multicolumn{6}{|c|}{ CYP2E1 (rs2070676) } \\
\hline C allele & $610(80.9 \%)$ & $322(83.4 \%)$ & $288(78.3 \%)$ & 1.000 (reference) & \\
\hline G allele & $144(19.1 \%)$ & $64(16.6 \%)$ & $80(21.7 \%)$ & $1.398(0.970-2.013)$ & $p=0.072$ \\
\hline \multicolumn{6}{|c|}{ CYP2E1 (rs2515641) } \\
\hline C allele & $590(78.3 \%)$ & $319(82.6 \%)$ & $271(73.6 \%)$ & 1.000 (reference) & \\
\hline $\mathrm{T}$ allele & $164(21.7 \%)$ & $67(17.4 \%)$ & $97(26.4 \%)$ & $1.704(1.200-2.421)$ & $p=0.003 *$ \\
\hline \multicolumn{6}{|c|}{ NAT2 (rs1495741) } \\
\hline G allele & $398(52.8 \%)$ & $220(57.0 \%)$ & $178(48.4 \%)$ & 1.000 (reference) & \\
\hline A allele & $356(47.2 \%)$ & $166(43.0 \%)$ & $190(51.6 \%)$ & $1.415(1.062-1.885)$ & $p=0.018$ * \\
\hline \multicolumn{6}{|c|}{ NAT2 (rs1799930) } \\
\hline G allele & $566(75.1 \%)$ & $286(74.1 \%)$ & $280(76.1 \%)$ & 1.000 (reference) & \\
\hline A allele & $188(24.9 \%)$ & $100(25.9 \%)$ & $88(23.9 \%)$ & $0.899(0.646-1.251)$ & $p=0.528$ \\
\hline
\end{tabular}

Note: ${ }^{*}$ and bold text indicated a significant association with $p$-value $<0.05$.

\section{Discussion}

In this study, we investigated the significance of the relationship between ADR in patients with LTBI receiving the $3 \mathrm{HP}$ regimen and several drug metabolic enzyme gene polymorphisms of CYP5A6, CYP2B6, CYP2C19, CYP2E1, and NAT2 in the Taiwanese population. Results showed that almost half of the participants $(184 / 377,48.8 \%$ ) experienced ADRs (98.3\% were < Grade 2$)$, and the most common presentation was flu-like symptoms, accounting for $80.2 \%$ of ADR episodes, which is much higher than that reported in a previous study [6]. Our study results indicated that the high incidence of flu-like symptoms is the major problem associated with the prescription of 3HP short-term treatment for LTBI cases. This is another aspect that should be further investigated.

INH is an inhibitor of cytochrome P450 [9,10]; by contrast, rifapentine is an inducer of cytochrome P450 [8,12], which may result in pharmacodynamic reduction in the treatment regimen. Our study showed that cytochrome P450 enzymes, such as CYP2B6 and CYP2E1, were associated with the incidence of ADR $(p<0.05)$. Some of these enzymes are involved in the metabolic pathway of INH, such as CYP2E1 and NAT2 [13,14], and some have direct or indirect effects on INH, such as CYP2B6 [15]. Based on our study results, the occurrence of side effects appeared to be more related to INH. Thus, the relationship between INH and flu-like symptoms is worth examining because the major side effects of the 3HP treatment are flu-like symptoms.

The $3 \mathrm{HP}$ regimen contained 3 times higher doses, especially for INH, when compared with other regimens. However, based on animal studies, high doses of INH have no greater efficacy than standard doses (300 mg) [16]. By contrast, significant differences in drug tolerance, ADRs, and safety were not observed between the high and normal doses of rifapentine [17-20]. Rifapentine acts as an inducer of many metabolic enzymes, especially in antiretroviral drugs; thus, interactions between INH and rifapentine have been evaluated in many studies [21,22]. In 2018, Brooks et al. indicated that serious 
drug side effects are associated with endogenous cytokines [23]. Therefore, we speculate that high doses of INH can induce side effects of rifapentine, coupled with the effects of certain genotypes, resulting in more drug side effects in many cases. However, this hypothesis must be explored and confirmed by conducting additional molecular biology, pharmacokinetics, and pharmacodynamics studies, and even animal experiments.

This study aimed to determine whether the side effects of LTBI 3HP treatment (INH and rifapentine) are associated with SNPs. Many studies have discussed the association between genotypes and drug side effects [24-26]; with the rise of pharmacogenetics and pharmacogenomics in recent years [27-29], in addition to the current focus on personalized medicine, the results of this study are expected to be personalized in TB.

Several genotypes (rs8192709 TC, rs2070676 CG, rs2515641 CT, and rs1495741 AA) showed an association with side effects to LTBI in our study. The results indicate that for patients with the rs8192709 TC genotype, the risk of side effects is 2.355 folds higher than that for patients with the TT genotype. Furthermore, patients with the rs2070676 CG genotype, rs2515641 CT genotype, and rs1495741 AA genotype had higher risks of side effects $(p=0.036, p=0.006$, and $p=0.018$, respectively) than did patients with other genotypes (Table 3). Additionally, rs2515641 T and rs1495741 A allele carriers belong to a high-risk group for side effects ( $p=0.003$ and $p=0.018$, respectively) (Table 4). Hiratsuka et al. have suggested that SNPs of NAT2 enzymes can predict the side effects of INH [30]. Similarly, Sotsuka et al. indicated that hepatotoxicity caused by INH is related to the genotype of its drug-metabolizing enzyme [31]. Additionally, the genotype of NAT2 is associated with failure or recurrence of TB treatment [21]. Most of the studies have investigated the relationship between INH and genotypes. By contrast, few studies have focused on the relationship between rifapentine and genotypes; this may be due to the metabolic pathway of rifapentine, which is still unclear, thus hindering further research on genetic polymorphisms.

\section{Conclusions}

In summary, we found that CYP2C19 rs4986893, CYP2E1 rs2070676, and CYP2E1 rs2515641 were associated with ADR development. Since CYP2C19 and CYP2E1 have been proven to be involved in the metabolic pathway of INH, their association with ADR development is a rational supposition. The results of this study can provide an improved strategy for identifying people with increased TB risk.

Author Contributions: Conceptualization: Y.-Y.Y., S.-M.T., H.-L.C., and Y.-W.H.; methodology: W.-W.C. and S.-F.Y.; formal analysis: S.-F.Y.; resources: S.-M.T., W.-T.Y., W.-C.H., C.-H.L., and Y.-W.H.; writing-original draft preparation: Y.-Y.Y., S.-M.T., W.-W.C., H.-L.C., and Y.-W.H.; writing-review and editing; Y.-Y.Y., S.-M.T., S.-F.Y., H.-L.C., and Y.-W.H. All authors have read and agreed to the published version of the manuscript.

Funding: This research received no external funding.

Conflicts of Interest: The authors declare no conflict of interest.

\section{References}

1. Dye, C.; Scheele, S.; Dolin, P.; Pathania, V.; Raviglione, M.C. Consensus statement. Global burden of tuberculosis: Estimated incidence, prevalence, and mortality by country. Who global surveillance and monitoring project. JAMA 1999, 282, 677-686. [CrossRef] [PubMed]

2. Sterling, T.R.; Villarino, M.E.; Borisov, A.S.; Shang, N.; Gordin, F.; Bliven-Sizemore, E.; Hackman, J.; Hamilton, C.D.; Menzies, D.; Kerrigan, A.; et al. Three months of rifapentine and isoniazid for latent tuberculosis infection. N. Engl. J. Med. 2011, 365, 2155-2166. [CrossRef] [PubMed]

3. Centers for Disease Control and Prevention (CDC). Recommendations for use of an isoniazid-rifapentine regimen with direct observation to treat latent mycobacterium tuberculosis infection. MMWR. Morb. Mortal. Wkly. Rep. 2011, 60, 1650-1653. 
4. Doan, T.N.; Fox, G.J.; Meehan, M.T.; Scott, N.; Ragonnet, R.; Viney, K.; Trauer, J.M.; McBryde, E.S. Cost-effectiveness of 3 months of weekly rifapentine and isoniazid compared with other standard treatment regimens for latent tuberculosis infection: A decision analysis study. J. Antimicrob. Chemother. 2019, 74, 218-227. [CrossRef] [PubMed]

5. Bliven-Sizemore, E.E.; Sterling, T.R.; Shang, N.; Benator, D.; Schwartzman, K.; Reves, R.; Drobeniuc, J.; Bock, N.; Villarino, M.E. Three months of weekly rifapentine plus isoniazid is less hepatotoxic than nine months of daily isoniazid for LTBI. Int. J. Tuberc. Lung Dis. 2015, 19, 1039-1044. [CrossRef] [PubMed]

6. Sterling, T.R.; Moro, R.N.; Borisov, A.S.; Phillips, E.; Shepherd, G.; Adkinson, N.F.; Weis, S.; Ho, C.; Villarino, M.E. Flu-like and other systemic drug reactions among persons receiving weekly rifapentine plus isoniazid or daily isoniazid for treatment of latent tuberculosis infection in the prevent tuberculosis study. Clin. Infect. Dis. Off. Publ. Infect. Dis. Soc. Am. 2015, 61, 527-535. [CrossRef]

7. Huang, Y.W.; Yang, S.F.; Yeh, Y.P.; Tsao, T.C.; Tsao, S.M. Impacts of 12-dose regimen for latent tuberculosis infection: Treatment completion rate and cost-effectiveness in Taiwan. Medicine 2016, 95, e4126. [CrossRef]

8. Baciewicz, A.M.; Chrisman, C.R.; Finch, C.K.; Self, T.H. Update on rifampin, rifabutin, and rifapentine drug interactions. Curr. Med Res. Opin. 2013, 29, 1-12. [CrossRef]

9. Desta, Z.; Soukhova, N.V.; Flockhart, D.A. Inhibition of cytochrome p450 (cyp450) isoforms by isoniazid: Potent inhibition of cyp2c19 and cyp3a. Antimicrob. Agents Chemother. 2001, 45, 382-392. [CrossRef]

10. Wen, X.; Wang, J.S.; Neuvonen, P.J.; Backman, J.T. Isoniazid is a mechanism-based inhibitor of cytochrome p450 1a2, 2a6, 2c19 and 3a4 isoforms in human liver microsomes. Eur. J. Clin. Pharmacol. 2002, 57, 799-804. [CrossRef]

11. Tung, M.C.; Wen, Y.C.; Wang, S.S.; Lin, Y.W.; Chow, J.M.; Yang, S.F.; Chien, M.H. Impact of long non-coding RNA hotair genetic variants on the susceptibility and clinicopathologic characteristics of patients with urothelial cell carcinoma. J. Clin. Med. 2019, 8, 282. [CrossRef] [PubMed]

12. Williamson, B.; Dooley, K.E.; Zhang, Y.; Back, D.J.; Owen, A. Induction of influx and efflux transporters and cytochrome p450 3a4 in primary human hepatocytes by rifampin, rifabutin, and rifapentine. Antimicrob. Agents Chemother. 2013, 57, 6366-6369. [CrossRef] [PubMed]

13. Perwitasari, D.A.; Atthobari, J.; Wilffert, B. Pharmacogenetics of isoniazid-induced hepatotoxicity. Drug Metab. Rev. 2015, 47, 222-228. [CrossRef] [PubMed]

14. Wang, P.; Pradhan, K.; Zhong, X.B.; Ma, X. Isoniazid metabolism and hepatotoxicity. Acta Pharm. Sin. B 2016, 6, 384-392. [CrossRef] [PubMed]

15. Fernandes, D.C.; Santos, N.P.; Moraes, M.R.; Braga, A.C.; Silva, C.A.; Ribeiro-dos-Santos, A.; Santos, S. Association of the cyp2b6 gene with anti-tuberculosis drug-induced hepatotoxicity in a brazilian amazon population. Int. J. Infect. Dis. 2015, 33, 28-31. [CrossRef] [PubMed]

16. Cynamon, M.H.; Zhang, Y.; Harpster, T.; Cheng, S.; DeStefano, M.S. High-dose isoniazid therapy for isoniazid-resistant murine mycobacterium tuberculosis infection. Antimicrob. Agents Chemother. 1999, 43, 2922-2924. [CrossRef]

17. Weiner, M.; Burman, W.; Vernon, A.; Benator, D.; Peloquin, C.A.; Khan, A.; Weis, S.; King, B.; Shah, N.; Hodge, T. Low isoniazid concentrations and outcome of tuberculosis treatment with once-weekly isoniazid and rifapentine. Am. J. Respir. Crit. Care. Med. 2003, 167, 1341-1347. [CrossRef]

18. Bock, N.N.; Sterling, T.R.; Hamilton, C.D.; Pachucki, C.; Wang, Y.C.; Conwell, D.S.; Mosher, A.; Samuels, M.; Vernon, A. A prospective, randomized, double-blind study of the tolerability of rifapentine 600,900 , and 1,200 mg plus isoniazid in the continuation phase of tuberculosis treatment. Am. J. Respir. Crit. Care. Med. 2002, 165, 1526-1530. [CrossRef]

19. Lauzardo, M.; Ashkin, D. Optimizing the dose of rifapentine to treat tuberculosis. It's elementary. Am. J. Respir. Crit. Care. Med. 2015, 191, 251-252. [CrossRef]

20. Dorman, S.E.; Savic, R.M.; Goldberg, S.; Stout, J.E.; Schluger, N.; Muzanyi, G.; Johnson, J.L.; Nahid, P.; Hecker, E.J.; Heilig, C.M.; et al. Daily rifapentine for treatment of pulmonary tuberculosis. A randomized, dose-ranging trial. Am. J. Respir. Crit. Care. Med. 2015, 191, 333-343. [CrossRef]

21. Weiner, M.; Egelund, E.F.; Engle, M.; Kiser, M.; Prihoda, T.J.; Gelfond, J.A.; Mac Kenzie, W.; Peloquin, C.A. Pharmacokinetic interaction of rifapentine and raltegravir in healthy volunteers. J. Antimicrob. Chemother. 2014, 69, 1079-1085. [CrossRef] [PubMed] 
22. Podany, A.T.; Bao, Y.; Swindells, S.; Chaisson, R.E.; Andersen, J.W.; Mwelase, T.; Supparatpinyo, K.; Mohapi, L.; Gupta, A.; Benson, C.A.; et al. Efavirenz pharmacokinetics and pharmacodynamics in hiv-infected persons receiving rifapentine and isoniazid for tuberculosis prevention. Clin. Infect. Dis. 2015, 61, 1322-1327. [CrossRef] [PubMed]

23. Brooks, K.M.; George, J.M.; Pau, A.K.; Rupert, A.; Mehaffy, C.; De, P.; Dobos, K.M.; Kellogg, A.; McLaughlin, M.; McManus, M.; et al. Cytokine-mediated systemic adverse drug reactions in a drug-drug interaction study of dolutegravir with once-weekly isoniazid and rifapentine. Clin. Infect. Dis. 2018, 67, 193-201. [CrossRef] [PubMed]

24. Guzey, C.; Spigset, O. Genotyping of drug targets: A method to predict adverse drug reactions? Drug Saf. 2002, 25, 553-560. [CrossRef]

25. Guzey, C.; Spigset, O. Genotyping as a tool to predict adverse drug reactions. Curr. Top. Med. Chem. 2004, 4, 1411-1421. [CrossRef]

26. Wilke, R.A.; Lin, D.W.; Roden, D.M.; Watkins, P.B.; Flockhart, D.; Zineh, I.; Giacomini, K.M.; Krauss, R.M. Identifying genetic risk factors for serious adverse drug reactions: Current progress and challenges. Nat. Rev. Drug Discov. 2007, 6, 904-916. [CrossRef]

27. Rioux, P.P. Clinical trials in pharmacogenetics and pharmacogenomics: Methods and applications. Am. J. Health. Syst. Pharm. 2000, 57, 887-898; quiz 899-901. [CrossRef]

28. Daly, A.K. Pharmacogenomics of adverse drug reactions. Genome Med. 2013, 5, 5. [CrossRef]

29. Relling, M.V.; Evans, W.E. Pharmacogenomics in the clinic. Nature 2015, 526, 343-350. [CrossRef]

30. Hiratsuka, M.; Kishikawa, Y.; Takekuma, Y.; Matsuura, M.; Narahara, K.; Inoue, T.; Hamdy, S.I.; Endo, N.; Goto, J.; Mizugaki, M. Genotyping of the n-acetyltransferase2 polymorphism in the prediction of adverse drug reactions to isoniazid in japanese patients. Drug Metab. Pharmacokinet. 2002, 17, 357-362. [CrossRef]

31. Sotsuka, T.; Sasaki, Y.; Hirai, S.; Yamagishi, F.; Ueno, K. Association of isoniazid-metabolizing enzyme genotypes and isoniazid-induced hepatotoxicity in tuberculosis patients. In Vivo (Athens, Greece) 2011, 25, 803-812.

(C) 2019 by the authors. Licensee MDPI, Basel, Switzerland. This article is an open access article distributed under the terms and conditions of the Creative Commons Attribution (CC BY) license (http://creativecommons.org/licenses/by/4.0/). 